Freeze-dried extract stored at room temperature is suitable for at least nine months.

We should like to thank Dr. P. J. Sewell for his help with the freeze-drying of the extract.

REFERENCES

Cammarata, P. S., and Cohen, P. P. (1951). J. biol. Chem., 193, 53. Reitman, S., and Frankel, S. (1957). Amer. J. clin. Path., 28, 56.

\section{The extraction of Evans blue from plasma}

\author{
GEORGE DISCOMBE From the Central Middlesex \\ Hospital, London, N.W.10
}

It is possible to extract Evans blue quantitatively from plasma by the following procedure. Unfortunately, haem pigments and the yellow pigments of plasma are also extracted and make a substantial contribution to the absorption at the wavelength of the Evans blue absorption band but this can be corrected by a blank determination.

Evans blue forms a complex with benzalkonium chloride which can be extracted from the aqueous phase with $n$-butanol. Proteins are precipitated and after centrifugation form a tough layer at the interface. Since water and $n$-butanol are mutually soluble, the benzalkonium reagent is saturated with butanol, and kept at $+4^{\circ} \mathrm{C}$., thus ensuring that even at the end of the extraction process the temperature is slightly below ambient. If during centrifugation the temperature is allowed to rise above ambient on cooling the extract separates out into two phases and becomes turbid.

\section{REAGENTS}

Fifty per cent benzalkonium chloride U.S.P. (Marinol, Bayer Products) is diluted 1 in 8 with distilled water; a drop of concentrated hydrochloric acid is added to each $100 \mathrm{ml}$, and enough $n$-butanol to saturate it at $+4^{\circ} \mathrm{C}$., approximately $8 \mathrm{ml}$. per $100 \mathrm{ml}$. This reagent and $n$ butanol (A.R.) are kept in a refrigerator at $4^{\circ} \mathrm{C}$.

PROCEDURE

This procedure is designed for the Unicam SP 350 or Coleman junior absorptiometer or other instrument requiring 2.5 to $2.8 \mathrm{ml}$. samples.

Place $5 \mathrm{ml}$. benzalkonium reagent in a centrifuge tube and add $2 \mathrm{ml}$. dyed plasma and $3 \mathrm{ml} . n$-butanol. Cover with Parafilm, shake vigorously, and centrifuge at 3,000 r.p.m. for four to five minutes. Transfer the clear supernatant to a clean tube or directly to the cuvette, and read against a $n$-butanol blank at $605 \mathrm{~m} \mu$.

\section{BLOOD VOLUME DETERMINATIONS}

It is essential to prepare a blank from a sample collected before the dye is injected. It is not possible to correct by using measurements at $405 \mathrm{~m} \mu$, or to remove the interfering pigments.

I am indebted to Messrs. Bayer Products, Ltd., for gifts of benzalkonium chloride and of other alkyl benzyldimethylammonium chlorides.

Received for publication 5 May 1961 